\title{
Replacing a double-lumen tube with a single-lumen tube or a laryngeal mask airway device to reduce coughing at emergence after thoracic surgery: a randomized controlled single-blind trial Remplacement de la sonde double lumière par une sonde à une seule lumière ou un masque laryngé pour réduire la toux lors du réveil suivant une chirurgie thoracique: une étude randomisée contrôlée en simple aveugle
}

\author{
Issam Tanoubi, MD • Joanna Ng Man Sun, MD • Pierre Drolet, MD • \\ Louis-Philippe Fortier, MD • François Donati, PhD, MD
}

Received: 3 November 2014/Accepted: 12 May 2015/Published online: 19 May 2015

(c) Canadian Anesthesiologists' Society 2015

\begin{abstract}
Background Coughing episodes occur frequently at extubation after thoracic surgery, and this may be due in part to the double-lumen tube (DLT). In this study, the DLT was replaced with either a single-lumen endotracheal tube (ETT) or a laryngeal mask airway (LMA) device or left in place, and the incidence of coughing at emergence was compared between the three groups.

Methods Fifty-eight adults scheduled for thoracic surgery with a DLT were included. Exclusion criteria were an anticipated difficult airway, obesity, and contraindication to
\end{abstract}

This study was performed at the Department of Anesthesiology, Hôpital Maisonneuve Rosemont, a Université de Montréal affiliated centre.

Author contributions Issam Tanoubi, Pierre Drolet, and François Donati contributed to the study design. Issam Tanoubi wrote the study protocol. Issam Tanoubi, Joanna Ng Man Sun, Pierre Drolet, Louis-Philippe Fortier, and François Donati participated in patient recruitment and manuscript preparation. Issam Tanoubi, Joanna $\mathrm{Ng}$ Man Sun, and Pierre Drolet participated in the data analysis.

I. Tanoubi, MD $(\varangle) \cdot$ P. Drolet, MD · L.-P. Fortier, MD

F. Donati, PhD, MD

Département d'anesthésiologie, Université de Montréal, Hôpital

Maisonneuve-Rosemont, 5415 boulevard de l'Assomption,

Montréal, QC H1T 2M4, Canada

e-mail: i.tanoubi@umontreal.ca

J. N. M. Sun, MD

Département d'anesthésiologie, Hôpital Charles-LeMoyne,

Greenfield Park, QC, Canada the use of an LMA ProSeal ${ }^{T M}$ (LMA-P). After surgery but before emergence, patients were randomized to having the DLT (1) removed and replaced by an LMA-P (LMA-P Group), (2) removed and replaced by an ETT (ETT Group), or (3) left in place (DLT Group). The primary outcome was the number of coughing episodes at extubation.

Results Among 184 patients screened, 124 did not meet inclusion criteria, and two patients, both in the ETT Group, were excluded after randomization, leaving 20, 18, and 20 patients in the LMA-P, ETT, and DLT Groups, respectively. There were fewer coughing episodes (median [quartiles]) in the LMA-P Group than in the DLT Group (0[0-1] vs 2 [1-3], respectively; $P=0.01)$. In the DLT Group, $90 \%$ of patients coughed at least once. This incidence was not significantly different in the ETT Group (83\%; $P=0.222)$ but was significantly reduced in the LMA-P Group (35\%; $P<0.001)$. No patient had oxygen desaturation during airway exchange or at extubation. The incidence and severity of hoarseness and sore throat were similar in all groups.

Conclusion Coughing at extubation after thoracic surgery can be reduced if the DLT is replaced by an LMA-P before emergence. The number of patients in this trial was too small to evaluate the risks associated with exchanging the airway device. This trial was registered at ClinicalTrials.gov: NCT00925613.

Résumé

Contexte Les épisodes de toux surviennent fréquemment lors de l'extubation après une chirurgie thoracique, et ils pourraient être provoqués en partie par la sonde double 
lumière (SDL). Dans cette étude, nous avons remplacé la SDL par une sonde endotrachéale (SET) simple lumière, par un masque laryngé (ML) ou l'avons laissée en place, et nous avons comparé l'incidence de toux au réveil dans les trois groupes.

Méthode Cinquante-huit adultes devant subir une chirurgie thoracique avec une SDL ont été recrutés pour cette étude. Les critères d'exclusion étaient des voies aériennes anticipées comme difficiles, l'obésité et toute contre-indication à l'utilisation d'un masque laryngé ProSeal $^{T M}(M L-P)$. Après la chirurgie mais avant le réveil, les patients ont été aléatoirement attribués à l'un des trois groupes suivants: (1) retrait de la SDL et remplacement par un ML-P (groupe $M L-P$ ), (2) retrait et remplacement de la SDL par une SET (groupe SET), ou (3) SDL laissée en place (groupe SDL). Le critère d'évaluation principal était le nombre d'épisodes de toux lors de l'extubation.

Résultats Parmi les 184 patients évalués, 124 ne répondaient pas aux critères d'inclusion, et deux patients du groupe SET ont été exclus après la randomisation, laissant 20, 18 et 20 patients dans les groupes ML-P, SET et $S D L$, respectivement. Il y a eu moins d'épisodes de toux (médianes [quartiles]) dans le groupe ML-P que dans le groupe SDL (0 [0-1] vs 2 [1-3], respectivement; $P=0,01)$. Dans le groupe SDL, $90 \%$ des patients ont toussé au moins une fois. Cette incidence n'était pas significativement différente dans le groupe SET (83\%; $P=0,222)$, mais elle était significativement réduite dans le groupe ML-P (35\%; P<0,001). Aucun patient n'a subi de désaturation en oxygène pendant l'échange de sonde ou l'extubation. L'incidence et la gravité de l'enrouement et des maux de gorge étaient semblables dans tous les groupes.

Conclusion Les épisodes de toux lors de l'extubation suivant une chirurgie thoracique peuvent être réduits si on remplace la SDL par un ML-P avant le réveil. Le nombre de patients dans cette étude était trop restreint pour évaluer les risques associés au changement de dispositif pour les voies aériennes. Cette étude est enregistrée au ClinicalTrials.gov : NCT00925613.

Coughing at extubation can be a major concern, and there may be valid reasons to adopt measures to prevent this complication, at least in certain situations. The absence of coughing episodes improves patient comfort and may be particularly important after certain procedures, such as in neurosurgery $^{1}$ or ophthalmic surgery. ${ }^{2}$ Coughing and certain respiratory complications have similar triggers from mechano- and chemoreceptors, ${ }^{3,4}$ and thus, coughing might be associated with respiratory complications (such as laryngospasm, oxygen desaturation, upper airway obstruction, and pulmonary edema) or with hemodynamic consequences (such as tachycardia and hypertension). ${ }^{5}$ Reported cases highlight the role of vigorous coughing in potentially favouring airway rupture related to mechanical tracheal intubation when a double-lumen tube (DLT) is used. ${ }^{6,7}$

Many pharmacological and non-pharmacological techniques have been used to reduce coughing at emergence in patients with single-lumen endotracheal tubes (ETTs) in place, ${ }^{8-12}$ but these methods have not been applied to the situation of DLTs used chiefly in thoracic surgery. When using a DLT, the overall chosen diameter is normally greater than that of an ETT, and the DLT is in contact with a greater area of the tracheobronchial tree, increasing the potential for cough stimuli. In addition, patients presenting for thoracic surgery often have a history of smoking, hyperreactive airways, and impaired pulmonary function and are at high risk for coughing at extubation.

The use of pharmacological methods to decrease coughing at extubation (lidocaine, narcotics, propofol) carries the risk of delaying extubation. Changing the DLT to an airway device that is likely to induce less stimulation to the airway might be an option. During thoracic surgery, it is common practice in certain centres to replace the DLT with an ETT, whether or not prolonged ventilation is contemplated. Evaluations are lacking on the effect of this tube exchange on coughing. Supraglottic airways are better tolerated than ETTs, and fewer respiratory complications during the recovery period have been reported when the ETT is replaced with a laryngeal mask airway device before emergence. ${ }^{12}$ This technique has been used in sporadic case reports. ${ }^{12-14}$

The goal of this study was to compare coughing at extubation in three situations after thoracic surgery was performed with a DLT in place: (1) replacing the DLT with a laryngeal mask airway device; (2) replacing the DLT with a single-lumen ETT; and (3) leaving the DLT in place. The primary outcome was the number of coughing episodes, and secondary outcomes were the number of subjects with no coughing episodes and side effects. We hypothesized that exchanging the DLT with either a single-lumen ETT or a laryngeal mask airway device after thoracic surgery would reduce the incidence of coughing at emergence.

\section{Methods}

The protocol was approved by the Comité d'éthique de la recherche of Hôpital Maisonneuve-Rosemont on February 10, 2009, and participants gave their written informed consent before surgery. The trial was a single-blind 
randomized study using a computer randomization table ${ }^{\mathrm{A}}$ with a control group. The study was carried out in the Department of Anesthesiology, Hôpital Maisonneuve Rosemont from April 2009-May 2011.

Fifty-eight adults were included in the study. Inclusion criteria were patients aged 18-75 yr, American Society of Anesthesiologists (ASA) physical status I-III, and scheduled for elective thoracic surgery under general anesthesia with tracheal intubation involving a DLT. Exclusion criteria were patients with an anticipated difficult intubation, gastroesophageal reflux, full stomach, body mass index $(\mathrm{BMI})>30 \mathrm{~kg} \cdot \mathrm{m}^{-2}$, allergy to the drugs used in the study, and/or a nasogastric tube in place at the time for tube exchange. Anticipated difficult intubation was defined as the presence of at least one of the following criteria $^{15}$ : mouth opening $<35 \mathrm{~mm}$, Mallampati class 3 or 4 , thyromental distance $<65 \mathrm{~mm}$, limited mandibular protrusion with retrognathia (when lower incisors cannot be advanced to meet upper incisors), neck extension $<35^{\circ}$ (estimated angle traversed by the occlusal surface of the upper teeth when the patient is asked to extend the head maximally), and previous difficult orotracheal intubation.

\section{Anesthesia}

In the operating room, a peripheral venous access was established, and the appropriate monitors (electrocardiogram, pulse oximeter, invasive blood pressure, and nerve stimulator) were placed as determined by the anesthesiologist in charge of the case. A thoracic epidural was inserted when indicated. Anesthesia was induced with fentanyl $2.5 \mu \mathrm{g} \cdot \mathrm{kg}^{-1}$ or sufentanil $0.25 \mu \mathrm{g} \cdot \mathrm{kg}^{-1}$, propofol $2 \mathrm{mg} \cdot \mathrm{kg}^{-1}$, and rocuronium $0.5 \mathrm{mg} \cdot \mathrm{kg}^{-1}$. When neuromuscular blockade was complete, defined as no response to train-of-four stimulation, intubation was performed under direct laryngoscopy using a Rusch $^{\circledR}$ Bronchopart $^{\mathrm{TM}}$ Carlens DLT with a spur (@Teleflex, Westmeath, Ireland). The size of the DLT was chosen by the anesthesiologist based on the patient's weight, height, sex, and the manufacturer's recommendations. Patients were excluded from the study if intubation was difficult, as defined by more than two attempts and/or the need to ask for a second operator.

After intubation, the patient's lungs were ventilated with an air-oxygen mixture, and minute volume was adjusted to keep end-tidal $\mathrm{CO}_{2}$ at $34-42 \mathrm{mmHg}$. The inspired oxygen fraction was set initially at 50\% and adjusted if needed throughout surgery. A halogenated agent (sevoflurane or desflurane according to the preference of the anesthesiologist) was used for maintenance of anesthesia,

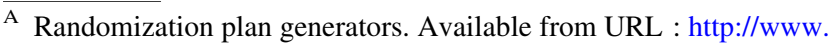
randomization.com (accessed April 2015).
}

with additional doses of fentanyl or sufentanil as required. Neuromuscular blockade was maintained with rocuronium to keep the response to train-of-four stimulation at two twitches or less.

\section{Randomization}

Group assignment was known only 20-30 min before the anticipated termination of surgery, at which time a sealed envelope was opened. Patients, not informed of their group assignment, were randomized into three groups: (1) LMA-P Group: the DLT was removed and replaced by an LMA ProSeal ${ }^{\mathrm{TM}}$ (Teleflex Inc. Triangle Park, NC, USA); (2) ETT Group: the DLT was removed and replaced by a single-lumen ETT; and (3) DLT Group: the DLT was left in place.

Airway device exchange procedure

\section{Endotracheal tube and LMA-P groups}

An airway device of the appropriate size was chosen. For the LMA-P, a size 4 was selected for females and a size 5 was chosen for males. For the ETT (@Covidien, Mallinckrodt, Mansfield, MA, USA; http://www.covidien. com/rms/brands/mallinckrodt), a size $7 \mathrm{~mm}$ internal diameter was used for females and a size 8 was used for males. The exchange procedure was as follows: The bronchial cuff was deflated, and the patient was turned from the lateral decubitus to the supine position and transferred to the stretcher. Vital signs were recorded and $100 \%$ oxygen was administered for three minutes, during which the halogenated agents were maintained and remifentanil $0.25-0.5 \mu \mathrm{g} \cdot \mathrm{kg}^{-1}$ was administered. The patient's mouth was suctioned for secretions $30 \mathrm{sec}$ to one minute before the intended device change. The DLT tracheal cuff was deflated and reinflated, and absence of a reaction to this maneuver was considered as an indication of appropriate depth of anesthesia. The tracheal cuff was then deflated and the DLT removed. The new airway device (LMA-P or ETT) was then inserted and connected to the breathing circuit.

If insertion of the LMA-P was unsuccessful, as judged by absence of a $\mathrm{CO}_{2}$ curve and/or leaks with a tidal volume of $7 \mathrm{~mL} \cdot \mathrm{kg}^{-1}$, a second attempt was made after deepening the anesthetic with propofol $0.5-1 \mathrm{mg} \cdot \mathrm{kg}^{-1}$ or remifentanil $0.2-0.3 \mu \mathrm{g} \cdot \mathrm{kg}^{-1}$. In case of failure of this second attempt, a single-lumen ETT was inserted.

In both the LMA-P and ETT Groups, vital signs were measured one and five minutes after the device change. After the exchange, the inspired oxygen fraction was set at the same value as before the maneuver. 


\section{Enrolment}

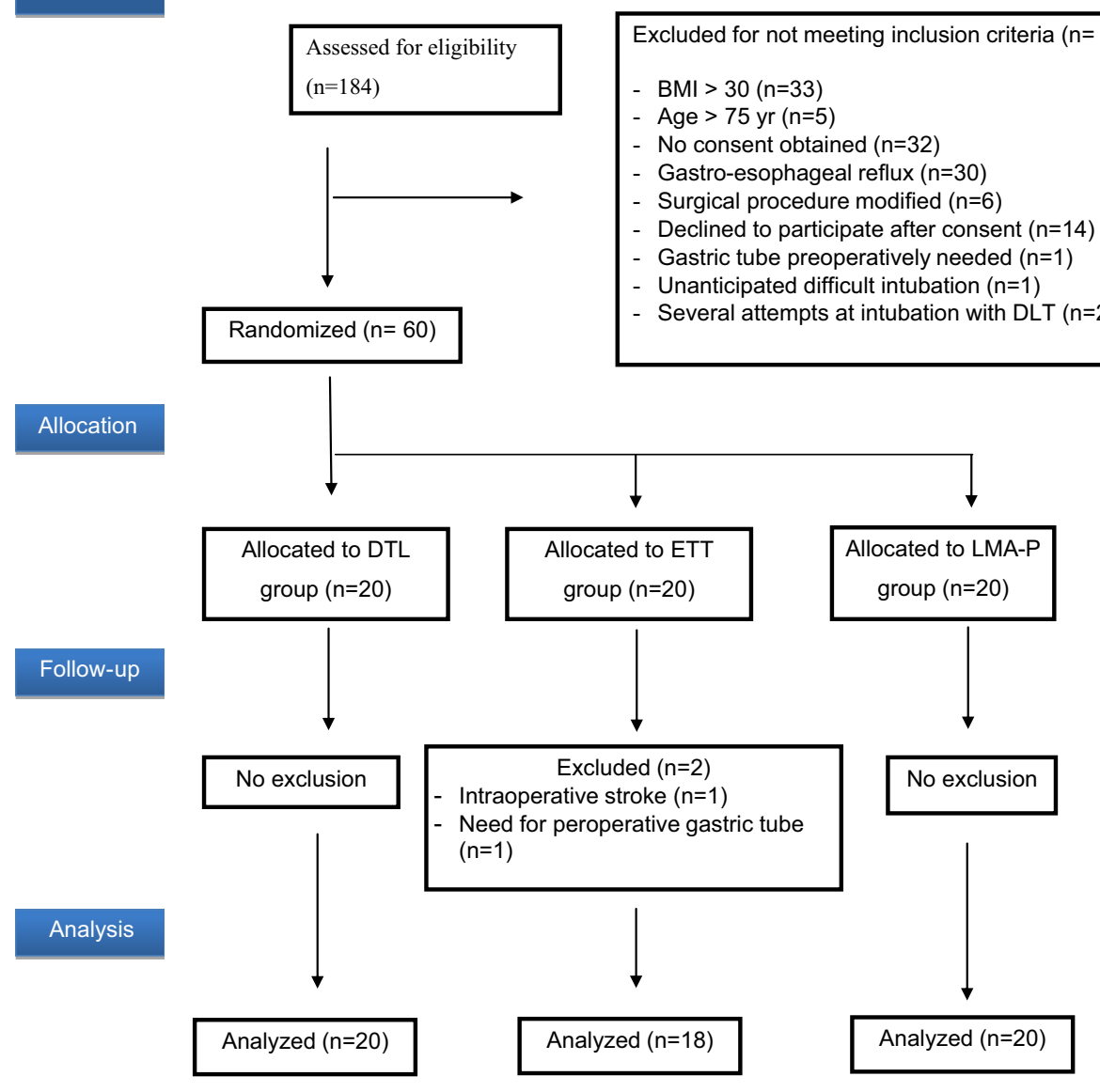

Fig. 1 Patient flow chart BMI = body mass index; DLT = double-lumen tube left in place; ETT = double-lumen tube changed for a single-lumen tube; LMA-P = double-lumen tube changed for an LMA ProSeal

\section{Double-lumen tube group}

In the DLT Group, the tube was left in place and depth of anesthesia was not altered.

In all groups, a neuromuscular reversal agent was administered; the halogenated agent was stopped; the patient was allowed to resume spontaneous ventilation; and the patient was transferred to the recovery room for tracheal extubation.

\section{Data collection}

Data were collected in the operating room and recovery room by a research nurse assigned to the project. The research nurse grading the post-extubation cough had to be present at extubation, and therefore, it was not possible to blind her to the type of airway device being used. The primary outcome variable was the number of coughing episodes at LMA-P removal or at ETT or DLT extubation. A coughing episode was defined as a forced inspiratory episode followed by a forced expiratory episode.
The following variables were also recorded during the airway device exchange: the number of subjects with no coughing episodes, the number of attempts at replacing the DLT with an LMA-P or an ETT, blood pressure and heart rate every minute after the exchange, and respiratory complications such as cough, laryngospasm, and inability to ventilate.

The time interval from the propofol/remifentanil dose for exchange to extubation and the time interval from arrival in the recovery room to removal of the airway device (time to extubation) were also measured. Arterial partial pressures of oxygen and carbon dioxide $\left(\mathrm{PaCO}_{2}\right)$ were also obtained from blood gas analysis after extubation.

Patients were interviewed at recovery room discharge to assess voice hoarseness and sore throat. For this study, locally developed scales (0-3) were used for hoarseness $(0$ $=$ absent; $1=$ reported by the patient; $2=$ noticed by the investigator; $3=$ produced aphonia $)$ and for sore throat $(0=$ absent; $1=$ mild; $2=$ moderate with pain becoming worse with swallowing; $3=$ severe with interference with feeding and need for analgesics). 
Data analysis

The Kolmogorov-Smirnov test was used to determine if the distribution of the number of coughing episodes was normal or non-normal. Comparison across the three groups was made using a one-way analysis of variance if distribution was normal or a Kruskal-Wallis test if distribution was non-normal, with appropriate post hoc tests. Other ordinal data were analyzed using the MannWhitney test. Categorical data were analyzed with a Chi square with Yates' correction test. All reported $P$ values are two sided. Statistical analysis was performed using the Prism $^{\mathrm{TM}}$ software for Mac OS X version 6.0d (GraphPad Software, Inc., La Jolla, CA, USA; www.graphpad.com).

\section{Sample size calculation}

In a preliminary study conducted in our department, ${ }^{\mathrm{B}}$ we compared the number of coughing episodes at emergence between two airway devices (ETT vs LMA-P). Patients with an ETT coughed 20 times on average with a standard deviation of 15. With an LMA-P, the number of coughing episodes was reduced to less than one. A decrease of 15 (from 20 to 5) was considered clinically significant. Therefore, using an alpha level of 0.05 and a beta value of $0.8,20$ participants per group were necessary. Thus, 60 patients were recruited for the study.

\section{Results}

From April 2009-May 2011, 58 patients completed the study (Figure). Demographic data, surgery characteristics, and anesthesia techniques are shown in Table 1. The groups were comparable with respect to age, BMI, ASA physical status, intubation score, Cormack-Lehane class, epidural analgesia, desflurane use, number of video-assisted thoracoscopic procedures, surgical procedure, and fentanyl or equivalent fentanyl dose. Compared with the other two groups, the LMA-P Group included more females and fewer active smokers. The distribution of coughing episodes was found to be non-normal; therefore, the Kruskal-Wallis test with Dunn's multiple comparison post-test was used. The median [interquartile range] number of coughing episodes was significantly less in the LMA-P Group than in the DLT Group (0 [0-1] vs 2 [1-3], respectively; $P=0.011)$. There was no significant difference in the number of coughing episodes between the ETT Group (1[0-3]) and the DLT Group. Eighteen $(90 \%)$ patients coughed at least once in the DLT

\footnotetext{
$\overline{\mathrm{B}}$ Deep extubation and insertion of a laryngeal mask airway reduces coughing at emergence. Geneviève Brouillette, MD, François Donati, $\mathrm{PhD}$, MD, FRCPC, Pierre Drolet, MSc, MD, FRCPC.
}

Table 1 Demographic data, surgery characteristics, and anesthesia techniques

\begin{tabular}{|c|c|c|c|}
\hline Group & DLT & ETT & LMA-P \\
\hline$n$ (Number of patients) & 20 & 18 & 20 \\
\hline Males (\%) & 70 & 61 & 30 \\
\hline Age (yr) & $56(11)$ & $54(13)$ & $52(14)$ \\
\hline BMI $\left(\mathrm{kg} \cdot \mathrm{m}^{-2}\right)$ & $23(2)$ & $23(4)$ & $24(3)$ \\
\hline $\begin{array}{l}\text { ASA Physical Status } \\
\text { Classification I-II-III }\end{array}$ & $0-14-6$ & $2-8-8$ & $2-11-7$ \\
\hline Smokers $(\%)^{*}$ & 55 & 55 & 30 \\
\hline Cormack-Lehane Class : 1-2-3 & $17-2-1$ & $15-3-0$ & $18-2-0$ \\
\hline Epidural analgesia used (\%) & 85 & 50 & 70 \\
\hline Desflurane use (\%) & 100 & 88 & 100 \\
\hline VATS $(\%)$ & 30 & 50 & 30 \\
\hline \multicolumn{4}{|l|}{ Surgical procedure $(n)$} \\
\hline Wedge resection & 4 & 2 & 1 \\
\hline Lobectomy & 10 & 12 & 13 \\
\hline Pneumonectomy & 0 & 1 & 2 \\
\hline Pleura surgery & 2 & 1 & 3 \\
\hline Chest wall surgery & 2 & 0 & 0 \\
\hline Thoracoscopic lung biopsy & 2 & 2 & 1 \\
\hline $\begin{array}{l}\text { Fentanyl or equivalent fentanyl used, } \\
\mu \mathrm{g}(\mathrm{SD})\end{array}$ & $\begin{array}{l}272 \\
\quad(128)\end{array}$ & $\begin{array}{l}292 \\
\quad(121)\end{array}$ & $\begin{array}{l}218 \\
\quad(78)\end{array}$ \\
\hline
\end{tabular}

Age and body mass index (BMI) are expressed as mean (standard deviation). * Smokers included patients who stopped smoking during the week before surgery. ASA $=$ American Society of Anesthesiology; DLT = double-lumen tube; ETT = single-lumen endotracheal tube; LMA-P = LMA ProSeal; VATS = video-assisted thoracoscopic surgery

Group, $15(83 \%)$ patients coughed in the ETT Group, and seven $(35 \%)$ patients coughed in the LMA-P Group (Table 2). There was a statistically significant difference between the LMA-P and DLT Groups $(P<0.001)$ and between the LMA-P and ETT Groups $(P=0.028)$. There was no statistically significant difference between the ETT and DLT Groups $(P=0.222)$ (Table 2$)$.

The device exchange procedure occurred without incident except in one case in the LMA Group where laryngospasm was detected on LMA-P insertion. The LMA-P was left in place, and the problem resolved rapidly after a propofol bolus was injected and positive pressure ventilation was applied. There was no oxygen desaturation in any patient. Time to extubation, voice hoarseness, sore throat, and blood gas values were comparable between the groups (Table 2). No delayed complications were reported up to patient discharge.

\section{Discussion}

This study shows that exchanging a DLT for an LMA-P before emergence from anesthesia decreases both the incidence and severity of coughing at removal of the 
device. These results agree with the findings of previous case reports or case series. Groudine et al. ${ }^{13}$ describe a case where a laryngeal mask airway device was used after DLT extubation to provide positive pressure ventilation in the intensive care unit. In the three cases reported by Sasano et al., ${ }^{14}$ a laryngeal mask airway device was found to improve the quality of emergence in patients undergoing lung volume reduction for severe emphysema. According to the authors, changing a DLT for this supraglottic airway before emergence prevents coughing.

In our study, substituting a DLT with an ETT does not significantly decrease the incidence of coughing at extubation. Replacing the DLT with an ETT is suggested in reported cases ${ }^{16}$ and practiced by some anesthesiologists; however, few studies have addressed the impact of this technique. Even if this was not the primary outcome of the present study, it suggests that substituting a DLT with an ETT does not diminish the incidence of coughing at emergence. Even so, replacing the DLT with an ETT could be regarded as safer than inserting an laryngeal mask airway device because the airway is better secured with an ETT. There may be a greater risk of laryngospasm with supraglottic devices than with an ETT. In the present study, a short episode of laryngospasm occurred at LMA-P insertion, but it was managed easily without desaturation with the injection of additional propofol. Nevertheless, our study was not designed to evaluate the safety of this practice because it was underpowered to compare the risks of airway exchange with the risk associated with coughing with a DLT left in place.

There were fewer coughing episodes in the LMA-P Group than in the ETT Group, but the difference was not statistically significant in our study. The reduction of the number of coughing episodes with the LMA-P corroborates results from previous studies. Koga et al. ${ }^{12}$ found fewer respiratory complications, including less coughing, in patients who had their ETT replaced with an laryngeal mask airway device before emergence. A case reported by Umegaki et al. ${ }^{17}$ describes a patient who had an ETT inserted nasotracheally for a cervical spine stabilization procedure. The ETT was replaced with the supraglottic airway with the patient under deep anesthesia. At emergence, the patient did not cough and did not move his cervical spine. In a previous study performed in our department, the incidence of coughing at emergence was reduced significantly if the ETT was replaced with the laryngeal mask airway device while the patient was still under deep anesthesia.

In our patients, there was no difference in sore throat or voice hoarseness between groups. These complications were likely the result of trauma during intubation and/or

Table 2 Primary and secondary outcomes

Primary and secondary outcomes

\begin{tabular}{|c|c|c|c|c|}
\hline & DLT & ETT & LMA-P & $P$ value \\
\hline$n$ (Number of patients) & 20 & 18 & 20 & \\
\hline Number of coughing episodes, median [IQR] & $2[1-3]^{*}$ & $1[0-3]$ & $0[0-1]^{*}$ & 0.011 \\
\hline Subjects with no coughing episodes (\%) & $10 *$ & 16 & $65^{*}$ & $<0.001$ \\
\hline Time to extubation (min), median [IQR] & $12[9-21]$ & $10[8-13]$ & $8.5[6-11.75]$ & 0.131 \\
\hline $\begin{array}{l}\text { Time interval from remifentanil dose for exchange } \\
\text { to extubation (min), median [IQR] }\end{array}$ & N/A & 13 [11.25-20.50] & 14 [20.50-24.00] & 0.971 \\
\hline Hoarseness (0-1-2), $n$ & $9-1-10$ & $4-5-8 * *$ & $6-5-8 * *$ & 0.854 \\
\hline Sore throat $(0-1-2), n$ & $10-8-2$ & $11-4-2 * *$ & $13-5-1 * *$ & 0.497 \\
\hline $\mathrm{PaO}_{2}(\mathrm{mmHg})$, mean $(\mathrm{SD})$ & $161(57)$ & $126(53)$ & 153(91) & 0.183 \\
\hline $\mathrm{PaCO}_{2}(\mathrm{mmHg})$, mean $(\mathrm{SD})$ & $49(19)$ & $47(9)$ & $47(7)$ & 0.559 \\
\hline
\end{tabular}

Median number of coughing episodes is the primary outcome variable

A Kruskal-Wallis test was used to compare median time to extubation (non-normal distribution). $P$ values are from the Kruskal-Wallis test across all three groups. Mean [IQR] time interval from remifentanil dose for exchange to extubation (min) was compared using the Mann-Whitney test. A Chi square test was used for the other parameters

DLT = double-lumen tube; ETT = single-lumen endotracheal tube; IQR = interquartile range; LMA-P = LMA ProSeal; $\mathrm{PaO}_{2}=$ arterial oxygen pressure; $\mathrm{PaCO}_{2}=$ arterial $\mathrm{CO}_{2}$ pressure

*There was a statistically significant reduction in the number of coughing episodes in the LMA-P Group compared with the ETT Group (Dann's multiple comparison test)

*A Chi square with Yates' correction test was used to compare the number of subjects with no coughing episodes (secondary endpoint). There was a significant reduction in the number of patients who coughed in the LMA-P Group compared with the DLT Group $(P<0.001)$ and the ETT Group $(P=0.028)$

**Data not collected in one patient 
DLT manipulation rather than during extubation only. A lower incidence of sore throat and voice alterations has been reported with the use of a bronchial blocker instead of a DLT. ${ }^{18,19}$ Other perioperative complications associated with use of a DLT have been reported, including laryngeal edema $^{20}$ and bronchial rupture. ${ }^{21}$ There is lack of evidence that injury to the tracheobronchial tree might be present as a result of coughing at intubation. ${ }^{22}$

We administered remifentanil in the LMA-P and ETT Groups to obtain optimal conditions when exchanging the airway device. We suggest that administration of this drug did not prevent coughing at emergence, as the time interval from the injection of remifentanil to extubation was greater than the duration of action of the remifentanil. Also, the incidence of coughing was similar between the ETT and DLT Groups in spite of remifentanil being given only to the former.

Contrary to our expectations, the $\mathrm{PaCO}_{2}$ and time to extubation after stopping the halogenated agents were similar amongst all groups. In our experience, some patients are stimulated by the presence of the DLT in the trachea and possibly show deeper sedation after extubation. Some patients even require maneuvers to relieve airway obstruction after DLT removal. Consequently, a shorter extubation time with a higher $\mathrm{PaCO}_{2}$ was expected in the DLT Group. This lack of difference might be partly due to the fact that most patients in all groups received intravenous analgesics sparingly because of the intraoperative use of a thoracic epidural.

In our study, we used DLTs with spurs. It is difficult to determine how much irritation the carinal hook produced on the airways or how different the results would have been if DLTs without spurs had been used. Also, the selection of DLT size was based on patient characteristics because studies were lacking that linked this factor to the incidence of cough at extubation. The size of the DLT was not noted, but we assume, given the comparability of the demographic groups, that DLT size did not influence our results.

As our study was not designed to assess the safety of this cough prevention technique, we excluded patients who were likely to present with a difficult airway, even if these patients could benefit from this technique. ${ }^{23}$ It was ethically difficult to include these patients as long as we were not reasonably certain of the safety of the maneuver.

The objective of the study was to determine the impact of the exchange technique on coughing, and it was not designed to assess complications other than cough. Thus, the number of patients enrolled was insufficient to derive conclusions regarding major but rare complications such as laryngospasm. In addition, there is currently a lack of literature that clearly connects the incidence or severity of coughing during extubation to the occurrence of other respiratory complications such as desaturation, pulmonary edema, airway obstruction, or bronchial rupture.
Consequently, it is difficult to state that decreasing cough reduces respiratory complications.

The LMA-P Group with fewer coughing episodes included more females and fewer active smokers. Even if this difference was not statistically different, the demographic data might have affected the results.

Our work has limitations. First, the anesthesiologist in charge of the patients knew patient group allocation. Nevertheless, this information was made available only a few minutes before emergence, so it was not possible to modify the anesthetic plan to make it suitable for group selection. Second, the sample size was calculated based on the number of coughing episodes, and the study may not have had the power to address the safety issue associated with the exchange technique. Finally, we did not address the advantages and benefits associated with cough prevention at emergence after thoracic surgery. Identification of a short episode of laryngospasm in one patient in the LMA-P Group is a concern. The safety of the exchange technique to prevent cough at extubation must be weighed against the risk of other events such as laryngospasm. Further studies should be designed to answer this question.

In conclusion, exchanging a DLT for an LMA-P should be regarded as a non-pharmacological means of cough prevention at extubation and may be indicated under certain conditions.

Conflicts of interest None declared

\section{References}

1. Venkatesan T, Korula $G$. A comparative study between the effects of $4 \%$ endotracheal tube cuff lignocaine and $1.5 \mathrm{mg} / \mathrm{kg}$ intravenous lignocaine on coughing and hemodynamics during extubation in neurosurgical patients: a randomized controlled double-blind trial. J Neurosurg Anesthesiol 2006; 18: 230-4.

2. Katz SE, Lubow M, Jacoby J. Suck and spit, don't blow: orbital emphysema after decompression surgery. Ophthalmology 1999; 106: 1303-5.

3. McCool FD. Global physiology and pathophysiology of cough: ACCP evidence-based clinical practice guidelines. Chest 2006; 129(1 Suppl): 48S-53S.

4. Polverino $M$, Polverino $F$, Fasolino $M$, Ando F, Alfieri A, De Blasio $F$. Anatomy and neuro-pathophysiology of the cough reflex arc. Multidiscip Respir Med 2012; 7: 5.

5. Moein Vaziri MT, Jouybar R, Moein Vaziri N, Moein Vaziri N, Panah A. Attenuation of cardiovascular responses and upper airway events to tracheal extubation by low dose propofol. Iran Red Crescent Med J 2013; 15: 298-301.

6. Marty-Ane CH, Picard E, Jonquet O, Mary H. Membranous tracheal rupture after endotracheal intubation. Ann Thorac Surg 1995; 60: 1367-71.

7. Belyamani L, Kabiri H, Kamili ND. Tracheal rupture after intubation with a right double lumen tube (French). Can J Anesth 2008; 55: 192-4. 
8. Chang CH, Lee JW, Choi JR, Shim YH. Effect-site concentration of remifentanil to prevent cough after laryngomicrosurgery. Laryngoscope 2013; 123: 3105-9.

9. Lee JY, Lim BG, Park HY, Kim NS. Sufentanil infusion before extubation suppresses coughing on emergence without delaying extubation time and reduces postoperative analgesic requirement without increasing nausea and vomiting after desflurane anesthesia. Korean J Anesthesiol 2012; 62: 512-7.

10. Yamasaki H, Takahashi K, Yamamoto S, Yamamoto Y, Miyata $Y$, Terai $T$. Efficacy of endotracheal lidocaine administration with continuous infusion of remifentanil for attenuating tube-induced coughing during emergence from total intravenous anesthesia. J Anesth 2013; 27: 822-6.

11. D'Aragon F, Beaudet N, Gagnon V, Martin R, Sansoucy $Y$. The effects of lidocaine spray and intracuff alkalinized lidocaine on the occurrence of cough at extubation: a double-blind randomized controlled trial. Can J Anesth 2013; 60: 370-6.

12. Koga K, Asai T, Vaughan RS, Latto IP. Respiratory complications associated with tracheal extubation. Timing of tracheal extubation and use of the laryngeal mask during emergence from anaesthesia. Anaesthesia 1998; 53: 540-4.

13. Groudine SB, Lumb PD, Sandison MR. Pressure support ventilation with the laryngeal mask airway: a method to manage severe reactive airway disease postoperatively. Can J Anaesth 1995; 42: 341-3.

14. Sasano H, Sasano N, Hattori T, Tsubouchi H, Tsuda T, Katsuya $H$. Tracheal tube/laryngeal mask exchange to prevent coughing in lung volume reduction surgery (Japanese). Masui 2000; 49: 278-81.
15. Boisson-Bertrand D, Bourgain JL, Camboulives J, et al. Difficult intubation. French Society of Anesthesia and Intensive Care. A collective expertise (French). Ann Fr Anesth Reanim 1996; 15: 207-14.

16. Benumof $J L, W u D$. Tracheal tear caused by extubation of a double-lumen tube. Anesthesiology 2002; 97: 1007-8.

17. Umegaki T, Murao K, Asai T, Shingu K. Insertion of a laryngeal mask airway before removal of a nasotracheal tube in a patient after anterior spine surgery (Japanese). Masui 2006; 55: 451-3.

18. Zhong T, Wang W, Chen J, Ran L, Story DA. Sore throat or hoarse voice with bronchial blockers or double-lumen tubes for lung isolation: a randomised, prospective trial. Anaesth Intensive Care 2009; 37: 441-6.

19. Knoll H, Ziegeler S, Schreiber JU, et al. Airway injuries after one-lung ventilation: a comparison between double-lumen tube and endobronchial blocker: a randomized, prospective, controlled trial. Anesthesiology 2006; 105: 471-7.

20. Yazbek-Karam VG, Haswani RW, Karam HS, et al. Unusual case of difficult double-lumen endotracheal tube removal. J Clin Anesth 2009; 21: 514-6.

21. Kaloud H, Smolle-Juettner FM, Prause G, List WF. Iatrogenic ruptures of the tracheobronchial tree. Chest 1997; 112: 774-8.

22. Molins L, Buitrago LJ, Vidal G. Tracheal lacerations after intubation. Chest 1998; 114: 1793-4.

23. Nicholson A, Cook TM, Smith AF, Lewis SR, Reed SS. Supraglottic airway devices versus tracheal intubation for airway management during general anaesthesia in obese patients. Cochrane Database Syst Rev 2013; 9: CD010105. 